\title{
Comparison of expectations and beliefs about good teaching in an academic day release medical education program: a qualitative study
}

Thea ACM van Roermund ${ }^{1 *}$, Henk G Mokkink ${ }^{2}$, Ben JAM Bottema ${ }^{3}$, Chris van Weel ${ }^{4,5}$ and Albert JJA Scherpbier ${ }^{6}$

\begin{abstract}
Background: In a professional learner-centered(ness) educational environment, communication and alignment of expectations about teaching are indispensable. Professional education of residents could benefit from an analysis and comparison of teachers' and residents' educational expectations and beliefs. Our purpose is to identify success factors and barriers related to aligning expectations and beliefs and building a supportive professional learner-centered educational environment.
\end{abstract}

Methods: We conducted semi-structured individual interviews with teachers and semi-structured focus groups with residents. A single interview format was used to make it possible to compare the results. Data were analysed using a qualitative software package (AtlasTi). Data analysis steps were followed by the author team, which identified four domains of good teaching: personal traits, knowledge, relationships and teaching qualities.

Results: Teachers and residents agreed about the importance of personal professional characteristics like being a role model and having an open and enthusiastic attitude. They all thought that having a specific knowledge base was essential for teaching. Approaching residents as adult learners was found to be an important element of the learner-centred environment and it was agreed that teachers should take practical experiences to a higher level. However, teachers and residents had different expectations about the practical consequences of being a role model, adult learning, coaching and openness, and the type of knowledge that was needed in the professional development program. Communication about different expectations appeared to be difficult.

Conclusions: Teachers and residents agreed on a conceptual level about expectations and beliefs regarding good teaching, but disagreed on an executive level. According to the residents, the disagreement about good teaching was not the biggest barrier to creating alignment and a supportive professional relationship; instead, it was the absence of a proper dialogue regarding issues about expectations and beliefs.

Keywords: Educational expectations and beliefs, Teachers, Residents, Postgraduate day release program in medical education

\section{Background}

Under the influence of current educational theories, learnercenteredness has become the main focus of postgraduate medical education in the past 20 years [1-7]. In this learnercentered environment, residents are expected to actively take responsibility for their learning processes, make learning plans and express their learning needs to the teachers

\footnotetext{
* Correspondence: dvanroermund@hotmail.com

${ }^{1}$ Education \& Research Department, Fontys University of Applied Sciences,

PO Box 347, 5600 AH Eindhoven, The Netherlands

Full list of author information is available at the end of the article
}

[8-11]. Because the learning plans and needs should be aligned with the program's educational goals and the way teachers prefer to teach, it is important that residents and teachers be able to exchange expectations and beliefs about teaching. When these expectations and beliefs are not compatible, communication about differences should be possible $[1,12,13]$. Medical education research that compares teachers' expectations and beliefs with those of residents could be helpful in creating a supportive learner-centered environment by showing factors of success and barriers for teaching. 
The majority of training of residents takes place in practice. In some countries, training is supported by a program outside practice called the academic day release program, in which reflection on practical experiences in small group sessions is an important element [14-16]. Because the main purpose of the program is to support residents in learning and applying their knowledge in practice, alignment between teachers and residents is extremely important.

Teachers in the academic day release program are experienced doctors, and professionals who are otherwise engaged in health care, such as psychologists. They know how to act in a doctor-patient relationship or a psychologist-patient relationship and have experience in training the individual residents in their practices. However, they may have little experience with teaching groups of residents [14-16].

During their time in the academic release program, teachers discover that the concept of learner-centeredness means that they should balance teaching a group, the curriculum's purposes, the residents' expectations and beliefs about teaching, and their own personal beliefs about teaching [10,17]. In their turn, residents should balance asking for feedback on their performance, expressing their learning needs and discussing their expectations about teaching with their teachers $[6,18-21]$. Incongruities in this interaction process between the teacher and the resident do not necessarily pose a problem as long as both parties are able and encouraged to face and reflect on expectations and beliefs [22].

Studies that compare teachers' and learners' beliefs and expectations usually concern teaching in elementary and secondary schools [23-27]. As far as we know, research about educational expectations and beliefs in higher education has focused on either teachers or learners, but little attention has been paid to them both in formal learning sessions [24]. In this study, we compare teachers' and residents' beliefs in an academic day release program, in order to identify similarities that could support and differences that could hinder teaching in the learner-centered environment.

The study was conducted in the Netherlands, in the postgraduate program for General Practitioners (GPs), offered by the Departments for General Practice Training of the eight university medical centres. The program comprises two years of training in general practice, interspersed with one year in hospital and community services. Residents meet at their university's medical department one day per week to participate in the academic day release program. Small groups of 10 to 12 residents are coached by two teachers, including an experienced general practitioner and a behavioural scientist. They are both responsible for teaching the program as well as for coaching the professional development and for judging the performance and development of the residents.

Our research questions are:

1. What are teachers' and residents' expectations and beliefs about what and how to teach in an academic day release program?

2. Do they agree about what and how to teach?

3. Do teachers and residents communicate about what and how to teach in order to support a learner-centered environment?

\section{Methods \\ Design}

We conducted semi-structured individual interviews with teachers and semi-structured focus groups with residents. The transcripts of the interviews and focus groups were analysed separately. To enable the comparison of results, the same interview format was used for both teachers and residents (see Additional file 1).

The research method used complies with the Qualitative research review guidelines - RATS.

\section{Ethical approval}

This study was carried out in the Netherlands in accordance with the applicable rules concerning the review of research ethics committees and informed consent (The Research Ethics Committee of the Radboud University Nijmegen Medical Centre, file number CMO 2012/412).

\section{Participants}

This study involved teachers in the postgraduate academic day release programs for general practitioners and their resident groups.

\section{Inclusion criteria}

For the individual interviews, we invited teachers (general practitioners and psychologists) who had worked with the same group of residents in weekly sessions for at least three months. For the focus groups, we aimed to include only groups of at least five to six residents to ensure variety in their views. In order to be able to answer the question about communication, we decided to include teachers and resident groups who actually worked with each other.

\section{Data collection procedure}

Teachers were informed collectively about the interviews and invited for individual interviews with one of the researchers (TR). The interviews were conducted in the department for training of general practitioners in two university medical centres and lasted for 45 to 60 minutes. All interviews were recorded and transcribed verbatim. 
Teachers asked resident groups to participate and then one of the researchers (TR) informed the resident groups about the study and the interviews. All interviews lasted for 60 to 75 minutes and were recorded and transcribed verbatim.

Two departments were involved in the data collection: we interviewed 12 teachers and 7 resident groups from the first department and 5 teachers and 2 resident groups from the second department. After each individual interview and focus group, we checked whether new information had emerged. Interviewing continued until saturation was reached, which occurred after interviewing people from the second department.

\section{Data analysis: development of dimensions}

In accordance with Miles and Huberman's theory about qualitative data analysis [28], three consecutive phases were used for the individual and focus group interviews: data reduction by coding, data structuring by categorization and data interpretation by discussion. On the basis of this analysis, we developed a framework for comparison [29].

TR imported all interview transcripts into the AtlasTi software package and coded all items. The codes were used as a first coding dictionary. Two researchers (TR and HM) revised the coding dictionary together by removing code duplicates and discussing the codes until they reached consensus about covering the items. For data reduction, these researchers used the tree structure from the AtlasTi software package. They independently structured the codes and discussed their structures in order to identify dimensions of teaching. Four underlying dimensions were identified: (1) personal traits, (2) knowledge/expertise, (3) relationships/ communication and (4) teaching qualities.

To test the accuracy of the dimensions, BB, CW and AS structured a random sample of 45 items independently. Cohen's $\mathrm{k}$ was calculated for inter-rater reliability. Inter-rater reliability is the degree of agreement among raters. To test the accuracy, according to topical literature, a Cohen's $\kappa$ of .70 is acceptable [30]. Inter- rater agreement was .73-.76, which is sufficient.

Data interpretation by discussion was the connecting activity throughout the whole analysis process and during the decision-making process about relevant quotes.

\section{Data analysis: comparison}

To compare the teachers and residents, we used all relevant data that were connected to the four dimensions. The first analysis procedure (coding and structuring) provided a practical tool for this task. The data were summarized independently per dimension after discussion between the authors. An example of this procedure is shown in Table 1; it regards dimension 1: personal traits. After that, characteristic quotes were chosen to illustrate the findings.

\section{Results}

Table 2 presents the characteristics of the participants in the two departments for general practitioners' training.

In this section, we will first describe teachers' and residents' beliefs and expectations for each of the four dimensions: personal traits, knowledge, relationships and teaching qualities. Next, we will compare these expectations and beliefs to identify factors of success for and barriers to teaching in a learner-centered environment.

In the personal dimension, we found that teachers see 'openness' as revealing one's strengths and weaknesses, and they expect the residents to do the same. As a consequence, they strongly believe that residents should learn to deal with their own vulnerabilities by talking freely about their mistakes. For residents, openness means that teachers give transparent feedback and are willing to share their professional experience with them. They primarily see the teacher as a role model with professional strengths and leadership (Table 3).

As for knowledge, teachers thought they could rely on the knowledge they have gained from practical experience for teaching less experienced junior doctors. Their interpretation of relevant teaching knowledge is the knowledge of group dynamics and they viewed that as crucial to their teaching roles. The residents interpreted knowledge as medical expert knowledge, which would enable discussions about residents' experiences with difficult situations to be raised to a higher level (Table 4).

Regarding the dimension of communication and relationships, teachers were inclined to take a caring role. Although the teachers saw residents as adults and built an atmosphere of confidence, they thought they knew best. To the residents, confidence meant being able to

Table 1 Example of data analysis

\begin{tabular}{ll}
\hline $\begin{array}{l}\text { Personal traits by teachers } \\
\text { Relevant data }\end{array}$ & Personal traits by residents \\
\hline -Liking my job as a doctor is essential (GP1) & -We like a teacher who shows that he likes to teach (R8) \\
-For me it is important that a doctor is able to show vulnerability (GP2) & -Teachers should be open and critical about themselves (R1) \\
-I think humour is important and having fun during day release time is & -Things work out better in our group when a teacher is determined \\
too (GP3) & and powerful (R2) \\
-I teach the residents enthusiasm for the medical profession (GP4) & -We need an enthusiastic teacher who can communicate clearly (R6) \\
\hline
\end{tabular}


Table 2 Characteristics of the participants

\begin{tabular}{lllll}
\hline \multicolumn{2}{c}{ Teachers $(\mathbf{N}=\mathbf{1 7})$} & & Residents $(\mathbf{N}=\mathbf{1 0 0}, \mathbf{9}$ groups $)$ \\
\cline { 1 - 2 } \cline { 5 - 5 } Characteristic & Description & & Characteristic & Description \\
\hline Men & 10 & & Men & 19 \\
Women & 7 & Women & 81 \\
General practitioners & 9 & & First-year trainees & 4 groups \\
Behavioural scientists & 8 & & Second-year trainees & 2 groups \\
Age & $30-60$ years & & Third-year trainees & 3 groups \\
Work experience & $1-20$ years & Age & 25-45 years \\
\hline
\end{tabular}

talk freely about what they expect from their teachers. They admitted to occasional immature behavior, but they wanted their teachers to discuss mutual expectations with them on an equal basis and they also felt that teachers should stimulate and initiate an open exchange of views.

Coaching and giving support while simultaneously evaluating the residents' professional development were indicated to be conflicting roles because confidentiality is an important element of the educational atmosphere (Table 5).

Regarding the teaching dimension, teachers interpreted their coaching role as 'counselling' in terms of listening to residents' stories and encouraging them to examine what these stories meant to them in order to better understand their experiences. Residents interpreted teaching competence as being able to explain connections between theoretical and practical knowledge, being proactive and delivering a program that is on a par with continuing professional development programs for more experienced colleagues (Table 6).

\section{Comparison}

The results show that teachers and residents agreed about the importance of a teacher being a role model and having personal characteristics such as enthusiasm and openness. They also agreed that teachers should have a certain knowledge base and should treat residents as adult learners.

However, teachers and residents also had different expectations and beliefs in each of the dimensions. They did not agree about who should be open about what, the way residents should be treated, what kind of knowledge teachers should have and how this knowledge should be transmitted.

Regarding the third research question about communication between teachers and residents, we found that while teachers thought that they picked up issues in the residents group, residents stated that they hardly ever explicitly discussed beliefs and expectations. Residents thought that teachers should stimulate and initiate an open exchange of views. But when they took the initiative to give feedback, their feedback was not always welcome and residents felt like they were wasting their energy.

\section{Discussion}

In this study, we collected teachers' and residents' expectations and beliefs about teaching in the postgraduate academic day release program for general practitioners in the Netherlands. We then compared these beliefs and expectations in order to identify factors of success and barriers to a professional learner-centered environment. We found four dimensions of teaching that covered the expectations and beliefs: personal traits, knowledge/expertise, relationships/communication and teaching qualities.

General agreement was found in each of the dimensions:

- the teacher should be a role model, be enthusiastic and have an open attitude

- the teacher should have a certain knowledge base

- the teacher should acknowledge that residents are adult learners

- coaching and assessing are conflicting roles

Teachers and residents did not agree about how these beliefs and expectations should be made effective (i.e. which themes they should be open about, what kinds of knowledge should be conveyed by teachers, how teachers ought to act as coaches for adult learners and how they should deal with various teaching roles). To summarize, teachers and residents agreed at a conceptual level about expectations and beliefs regarding good teaching, but disagreed at an executive level.

Agreement between teachers and residents about their expectations and beliefs can be a factor of success for a

\section{Table 3 Personal traits dimension}

\begin{tabular}{lll}
\hline & Teachers & Residents \\
\hline Quotes & "Enthusiasm is what you really need in this work." (P-GP8) & "Being enthusiastic is the main thing." (P-R2) \\
& "Being a role model and being able to show one's vulnerability & "The teacher should be willing to show leadership and talk about his \\
is one of the most important qualities here. A doctor should be able & experiences as a role model." (P-R5). \\
to talk openly about his mistakes." (P-GP2) & "Teachers should be transparent in giving feedback." (R-R3) \\
\hline
\end{tabular}


Table 4 Knowledge/expertise dimension

\begin{tabular}{lll}
\hline Teachers & Residents \\
\hline Quotes "I don't need to know all the ins and outs of cardiac problems. My daily & "Teachers should be able to explain theoretical considerations \\
practical knowledge is sufficient for working with residents." (K-GP4) & underlying treatments and discuss the limitations of guidelines." (K-R4) \\
& "Group dynamics: that is what you have to learn about when you start & "The psychologist teacher should have higher-level knowledge about \\
working as a teacher. Because that is difficult to handle." (K-P2) & doctor-patient communication and how to deal with conflict." (K-R8) \\
\hline
\end{tabular}

learner-centered environment. In current research about the evaluation of teaching performance, Scheepers et al. [31] showed that teachers who have an 'agreeable professional attitude' are able to consciously discuss residents' learning needs and educational goals. These teachers are flexible when it comes to adapting residents' learning plans and needs to the goals of the educational program. Moreover, they point to residents' responsibilities with regard to learning.

Disagreement itself does not need to be a barrier to communication between teachers and residents in an academic day release program, but it can make it more difficult to align the residents' learning needs and plans to the educational purposes of the program. Researchers in communication identified communication and feedback as one of the most important issues affecting teacher-resident interaction that should enhance residents' professional growth [9,32,33]. The degree to which educational goals are achieved depends on both the teacher's and learner's abilities to negotiate with one another and resolve conflicts [32]. The residents in our study experienced the absence of a real dialogue that would contribute to aligning expectations and beliefs, while teachers seemed to be convinced that they brought up issues in the group and, moreover, that they knew what was best for the residents. Teachers seemed to take a paternalistic perspective in communication with residents [34]. This paternalistic attitude was common in medical practice from its ancient roots until the 1970s, when doctors came to see that professional paternalism towards patients is ethically unacceptable and that they should respect the patients' autonomy and informed consent [35]. In a paternalistic educational climate, teachers are likely to take over learning responsibilities from their residents instead of stimulating the residents to face and deal with these responsibilities. The absence of a real dialogue in the academic day release program can be a serious barrier to aligning expectations, beliefs and professional support.

Another possible barrier for a professional learnercentred environment in the educational model of the GP training program seemed to be the educational model. From current educational theories about the learner's responsibility for his learning process, one could assume that a learner-centred environment seems to offer the best climate for a dialogue about expectations and beliefs. In his meta-analysis, Cornelius-White [1] explained that learner-centred education is a model that originated in counselling and was based on the client-centred approach founded by Carl Rogers [36]. In this approach, a counsellor invites the client to speak freely about his or her experiences, desires and worries. According to McCombs [4] and Bingham and Sidorkin [37], empathy and honouring the learner's voice are key elements in a corresponding educational approach. The teachers in our study interpreted teaching as 'counselling' in correspondence with the psychological humanistic perspective and a modern educational concept of learner- centeredness. However, they seemed to ignore the residents' expectations that they would show leadership and expert knowledge and be proactive.

A third barrier could be the academic day release context itself. More specifically, the synergy of two teachers teaching one group of residents, could strengthen a barrier that keeps residents from expressing their expectations and learning needs. Research about co-teaching in higher education (i.e. two teachers, who have different

Table 5 Relationships/communication dimension

\begin{tabular}{|c|c|c|}
\hline & Teachers & Residents \\
\hline \multirow[t]{3}{*}{ Quotes } & $\begin{array}{l}\text { "Residents are adult learners; however, as teachers, we take care and } \\
\text { know what is best for them, although they sometimes disagree." } \\
\text { (R-GP6) }\end{array}$ & $\begin{array}{l}\text { "We want to be treated as adults, although we do not always act that } \\
\text { way." (R-R6) }\end{array}$ \\
\hline & $\begin{array}{l}\text { "Besides providing guidance and support, I also have to give feedback } \\
\text { on their professional development and these are conflicting roles." } \\
\text { (R-GP1) }\end{array}$ & $\begin{array}{l}\text { "Confidentiality is an important issue here, because coaching and } \\
\text { evaluation are in the hands of the same teachers." (R-R8) }\end{array}$ \\
\hline & $\begin{array}{l}\text { "If something happens in the group and the atmosphere is getting } \\
\text { worse, then I have to pick up some problematic issues in the group } \\
\text { dynamics." (R-P3) }\end{array}$ & $\begin{array}{l}\text { "I think a lot of energy is wasted because we hardly ever talk explicitly } \\
\text { about our expectations regarding certain issues. Teachers should } \\
\text { stimulate us to do so, but our feedback is not always welcome." (R-R7) }\end{array}$ \\
\hline
\end{tabular}


Table 6 Teaching dimension

\begin{tabular}{lll}
\hline Teachers & Residents \\
\hline Quotes & $\begin{array}{l}\text { "My inspiration comes from helping residents to analyse their } \\
\text { experiences in relation to personal growth." (T-P3) }\end{array}$ & "He should be able to make the translation from science to practice." (T-R1) \\
& "I learned to ask: what does this experience mean to your personal "I learned a lot from well-organized continuing education programs." (T-R9) \\
development from a counselling perspective?" (T-GP1) & \\
& "My mission is to show residents that a patient is a human being, "We appreciate a proactive way of teaching. Teachers who take teaching \\
not just a disease that has to be cured." (T-P6) & us as seriously as teaching experienced colleagues." (T-R6) \\
\hline
\end{tabular}

specialties, teaching in one group of students), indicates that it is important for the students' learning process to be transparent when teachers have different beliefs about what and how to teach [38-40]. When teachers are open about differences, students learn how to use differences as a source of discussion about their learning goals and needs $[41,42]$. In our study, teachers themselves strongly agreed about their teaching roles as counsellors and, together, they confirmed each other in these roles as the best fit for supporting learning in practice. On the basis of this confirmation, it is plausible that doctors and psychologists strengthened their own and each other's beliefs about teaching: "as teachers, we know what is best". As a result, residents got the feeling that "feedback is not welcome".

Finally, the struggle with teaching roles (counselling and assessing) in which confidence and confidentiality are essential, could hinder an open exchange of expectations in the professional learning environment. The teachers' goals were to contribute to the personal growth of residents and, accordingly, they believed that counselling was the most important role. According to Bandura [43], Parker et al [44] and DeShon and Gillespie [45], self-goals and increasing agency (i.e. personal control over one's environment) are the most fundamental aspects of human existence. Failure to establish agency is believed to be strongly related to poor self-esteem. In this psychological perspective it is likely that teachers tend to hold on to their beliefs instead of aligning these with the expectations of the residents and the educational program goals.

\section{Conclusion}

With respect to the four teacher characteristics personal traits, knowledge/expertise, relationships/communication and teaching qualities, teachers and residents agreed on a conceptual level about expectations and beliefs, but disagreed on an executive level. According to the residents, the disagreement about good teaching was not the biggest barrier to creating alignment and a supportive professional relationship; instead, it was the absence of a proper dialogue regarding issues about expectations and beliefs. Other barriers were the educational model of the GP training program, the academic day release context and the struggle with teaching roles.

\section{Future research}

Questions for further research could focus on what 'learner-centeredness' means in an academic day release learning environment that aims to support learning in practice, and on the conditions for communication about differences between teachers' and residents' expectations and beliefs about teaching. Research in this specific educational context could explore the effects of co-teaching.

Future research could also focus on how these themes can be investigated (i.e. what research methods are most suitable for searching for answers). One option is an organizational learning history method that focuses on the various perspectives of teachers and residents, starting with collecting and then selecting critical events that can be reflected upon.

\section{Strengths and limitations}

To our knowledge, this is one of the rare qualitative studies to critically compare teachers' and residents' beliefs and expectations about teaching roles in academic day release training. The study also offers insights into possible consequences of lack of communication about teaching in a learner-centered educational environment (e.g. how teachers can interpret their role as coach).

We should, however, also point out some limitations. The study was limited to the training of general practitioners in the Netherlands, in which day release training plays an important role. These Dutch programs are representative for formal learning programs, but comparable long-term relationships between teacher and resident groups in postgraduate formal training are not common throughout the world. Although our results are drawn from a local context, we think they can inform the work in other formal medical educational environments.

A second point of interest could be the complexity of the qualitative comparison methodology. We followed up on this complexity by conscientiously conducting and discussing the subsequent research steps with an experienced team of researchers. 


\section{Additional file}

\section{Additional file 1: Interview format.}

\section{Competing interests}

The authors declare that they have no competing interests.

\section{Authors' contributions}

TR was the principal researcher and wrote the article. All authors contributed equally to the data analysis. AS and CW supervised the study. All authors read and approved the final manuscript.

\section{Acknowledgements}

We wish to express our highest appreciation for all the teachers and residents who participated in this study and were willing to share their views with us. Furthermore, we thank the Translation and Editing Service of Maastricht University Language Centre for improving the English language of the manuscript.

\section{Author details}

${ }^{1}$ Education \& Research Department, Fontys University of Applied Sciences, PO Box 347, 5600 AH Eindhoven, The Netherlands. 'Department of Primary and Community Care, Radboud University Nijmegen Medical Centre, Nijmegen, The Netherlands. ${ }^{3}$ Department of Primary and Community Care, Radboud University Nijmegen Medical Centre, Nijmegen, The Netherlands. ${ }^{4}$ Department of Primary and Community Care, Radboud University Nijmegen Medical Centre, Nijmegen, The Netherlands. ${ }^{5}$ Australian Primary Health Care Research Institute, Australian National University, Canberra, Australia. ${ }^{6}$ Faculty of Health, Medicine and Life Sciences, Maastricht University, Maastricht, The Netherlands.

Received: 24 October 2013 Accepted: 9 September 2014 Published: 3 October 2014

\section{References}

1. Cornelius-White J: Learner-Centered Teacher-Student Relationships Are Effective: A Meta-Analysis. Rev Educ Res 2007, 77(1):113-143.

2. Lesky LG, Wilkerson L: Using "standardized students" to teach a learner-centered approach to ambulatory precepting. Acad Med 1994, 69(12):955-957.

3. Luskin J, Somers C, Wooding J, Levenstein C: Teaching health and safety: Problems and possibilities for learner-centered training. Am J Ind Med 1992, 22(5):665-676.

4. McCombs BL: Learner-centered psychological principles for enhancing education: Applications in school settings. In The challenge in mathematics and science education: Psychology's response. Edited by Penner LA, et al. Washington, DC, USA: American Psychological Association; 1993.

5. Wilkerson L, Irby DM: Strategies for improving teaching practices: a comprehensive approach to faculty development. Acad Med 1998 73(4):387-396.

6. Frank JR, Snell LS, Cate OT, Holmboe ES, Carraccio C, Swing SR, Harris P, Glasgow NJ, Campbell C, Dath D: Competency-based medical education: theory to practice. Med Teach 2010, 32(8):638-645

7. lobst WF, Sherbino J, Cate OT, Richardson DL, Dath D, Swing SR, Harris P, Mungroo R, Holmboe ES, Frank JR: Competency-based medical education in postgraduate medical education. Med Teach 2010, 32(8):651-656.

8. Haidet $\mathrm{P}$, Stein $\mathrm{H}$ : The role of the student-teacher relationship in the formation of physicians. J Gen Intern Med 2006, 21(1):16-20.

9. Sinai J, Tiberius RG, de Groot J, Brunet A, Voore P: Developing a Training Program to Improve Supervisor-Resident Relationships, Step 1: Defining the Types of Issues. Teach Learn Med 2001, 13(2):80-85.

10. Tiberius RG: The role of teacher-learner relationships in medical education. In International Handbook of Research in Medical Education 2, Volume 7. Edited by Norman G. Houten: Springer; 2002.

11. Tiberius RG, Billson JM: The social context of teaching and learning. New Dir Teach Learn 1991, 45:67-86.

12. Drinkwater CK: Vocational training for general practice: a comparison of the views of trainees and teachers. Br Med J 1972, 4:96-98.

13. Plaut SM, Baker D: Teacher-student relationships in medical education: Boundary considerations. Med Teach 2011, 33(10):828-833.
14. Pereira Gray D: Training for General Practice. Plymouth: MacDonald and Evans; 1982.

15. Rigby C: Half-day release in vocational GP training: a case study of redesign based on qualitative evaluation. Educ Prim Care 2010, 21(6):354-359.

16. Short NL: A Philosophy for the Day Release Course in Vocational Training. Med Teach 1987, 9(2):205-208.

17. Stillwaggon J: Performing for the Students: Teaching Identity and the Pedagogical Relationship. J Philos Educ 2008, 42(1):67-83.

18. Nothnagle MMDM, Goldman RP, Quirk ME, Reis SMDM: Promoting Self-Directed Learning Skills in Residency: A Case Study in Program Development. Acad Med 2010, 85(12):1874-1879.

19. Sargeant J: Toward a common understanding of self-assessment. J Contin Educ Health Prof 2008, 28(1):1-4

20. Sargeant J, Mann K, van der Vleuten C, Metsemakers J: "Directed" self-assessment Practice and feedback within a social context. J Contin Educ Health Prof 2008, 28(1):47-54.

21. Silver I, Campbell C, Marlow B, Sargeant J: Self-assessment and continuing professional development: The Canadian perspective. J Contin EduC Health Prof 2008, 28(1):25-31.

22. Trowler $P$, Cooper A: Teaching and Learning Regimes: Implicit theories and recurrent practices in the enhancement of teaching and learning through educational development programmes. High Educ Res Dev 2002, 21(3):221-240

23. Brok P, Bergen TCM, Brekelmans JMG: Convergence and divergence between students' and teachers' perceptions of instructional behaviour in Dutch secondary education. In Contemporary Approaches to Research on Learning Environments: World Views. Edited by Fisher D, Khine M. Singapore: World Scientific Pub Co Inc; 2004:125-160.

24. Northcote M: Educational Beliefs of Higher Education Teachers and Students: Implications for Teacher Education. Aust J Teach Educ 2009, 34(3):69-81.

25. Weinstein R: Reaching Higher: the Power of Expectations in Schooling. USA: Harvard University Press; 2002.

26. McKown C, Weinstein RS: Teacher expectations, classroom context, and the achievement gap. J Sch Psychol 2008, 46(3):235-261.

27. Norton L, Richardson JTE, Hartley J, Newstead S, Mayes J: Teachers' Beliefs and Intentions concerning Teaching in Higher Education. High Educ 2005, 50(4):537-571.

28. Miles M, Huberman A: Qualitative Data Analysis. A Methods Source Book. Thousand Oaks, California: Sage Publications, Inc; 2003.

29. Attride-Stirling J: Thematic networks: an analytic tool for qualitative research. Qual Res 2001, 1(3):385-405.

30. Pallant J: SPSS Survival Manual. Columbus, OH USA: McGraw-Hill Education EMEA; 2010

31. Scheepers RA, Lombarts KM, van Aken MA, Heineman MJ, Arah OA Personality traits affect teaching performance of attending physicians: results of a multi-center observational study. PLoS One 2014, 9(5):e98107

32. Frymier $A B$, Houser ML: The teacher-student relationship as an interpersonal relationship. Comm Educ 2000, 49(3):207-219.

33. Gorham J, Millette DM: A comparative analysis of teacher and student perceptions of sources of motivation and demotivation in college classes. Comm Educ 1997, 46(4):245-261.

34. Wall S: Self-Ownership and Paternalism. J Polit Philos 2009, 17(4):399-417.

35. Cigman R: How not to think: medical ethics as negative education. Med Health Care Philos 2013, 16(1):13-18.

36. Rogers C: Freedom to Learn: a View of What Education Might Become. Columbus Ohio USA: Merrill Publishing Co; 1969.

37. Bingham C, Sidorkin A: Aesthetics and the Paradox of Educational Relation. J Philos Educ 2000, 35(1):21-30

38. Bacharach $\mathrm{N}$ : What makes co-teaching work? Identifying the essential elements. Coll Teach Method Style J 2008, 4(3):43-48.

39. Buczinsky S, Sisserson K: School District and University Co-Teaching:Toward Instructional Synergy in an Induction/M.Ed. Program. Issues Teach Educ 2008, 17(1):47-74.

40. Kluth P, Straut D: Do as We Say and as We Do: Teaching and Modeling Collaborative Practice in the University Classroom. J Teach Educ 2003, 54(3):228-240.

41. Vaughn LM, Baker RC: Do Different Pairings of Teaching Styles and Learning Styles Make a Difference? Preceptor and Resident Perceptions. Teach Learn Med 2008, 20(3):239-247. 
42. Wilkes MMDP, Raven BHP: Understanding Social Influence in Medical Education. Acad Med 2002, 77(6):481-488.

43. Bandura A: Social cognitive theory: An agentic perspective. Annu Rev Psychol 2001, 52(1):1-26.

44. Parker PD, Martin AJ, Colmar S, Liem GA: Teachers' workplace well-being: Exploring a process model of goal orientation, coping behavior, engagement, and burnout. Teach Teach Educ 2012, 28(4):503-513.

45. DeShon RP, Gillespie JZ: A Motivated Action Theory Account of Goal Orientation. J Appl Psychol 2005, 90(6):1096-1127.

doi:10.1186/1472-6920-14-211

Cite this article as: van Roermund et al:: Comparison of expectations and beliefs about good teaching in an academic day release medical education program: a qualitative study. BMC Medical Education 2014 14:211.

\section{Submit your next manuscript to BioMed Central and take full advantage of:}

- Convenient online submission

- Thorough peer review

- No space constraints or color figure charges

- Immediate publication on acceptance

- Inclusion in PubMed, CAS, Scopus and Google Scholar

- Research which is freely available for redistribution 